\title{
Armenians face up to scenes of total devastation
}

\section{Moscow}

THE cataclysm that struck Armenia on 7 December claims as of 12 December 40,000 to 45,000 lives and tens of thousands wounded. Over half a million people have lost their homes. The town of Spitak with a population of 20,000 , at the epicentre of the worst earthquake in Armenia in the past thousand years, was levelled.

Eighty per cent of the homes and industrial structures were reduced to rubble in Leninakan, Armenia's second largest city (population: 290,000), and half of all structures in Kirovakan (population: $170,000)$. The earthquake hit an area with a population of more than 700,000 , toppling buildings and severing power, gas, telephone and other communication lines. These are preliminary estimates of the Armenian calamity.

President Mikhail Gorbachev cut short his visit in New York, postponed planned visits to Cuba and Britain and arrived in Armenia to take charge of the situation. Prime Minister Nikolai Ryzhkov has been in Yerevan right from the start, coordinating the rescue and salvage operations as head of a special CPSU (Soviet Communist Party) Politburo commission.

Other members of the commission working in Yerevan, the capital of

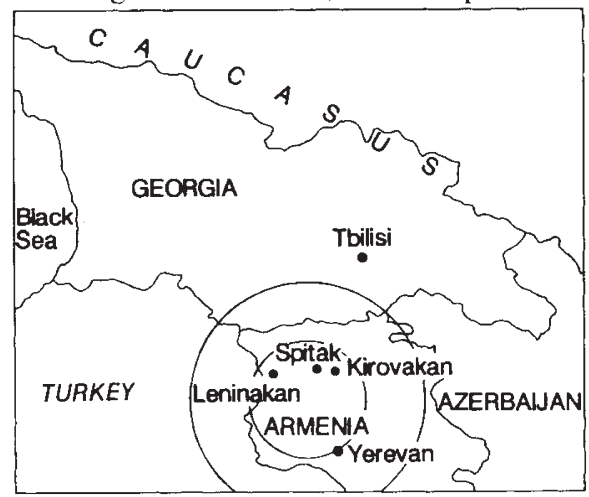

Area affected by last week's earthquake.

Armenia, include the ministers of defence and health and several high-ranking officials. Large numbers of experts, planefuls of special equipment, blood, plasma, medicine, food, tents, warm clothing and other prime necessities have been coming to Armenia from all over the Soviet Union and more than 40 foreign countries.

The earthquake hit the area on 7 December at 10:41 a.m. Moscow time. Within the next thirty minutes, nine seismological stations in Kizyl-Aravat, Tbilisi, Yeltsovka, Yakutsk, Uzhgorod, Moscow, Bakuriani, Tashkent and Ashkhabad sent emergency reports to the central seismic observatory at Obninsk, near Moscow.

Thirty minutes later the first urgent report of a powerful earthquake in Armenia reached the Council of Minis- ters. The report was based on seismic records of the tremor and on macroseismic occurrences in Tbilisi and Bakuriani, Georgia. Within the next thirty minutes, additional information arrived from twelve seismological stations. More accurate parameters of the calamity could not be had directly from the disaster area because the seismological station in Leninakan had been cut off.

The civil defence headquarters, the CPSU Central Committee and army units were informed of the earthquake just before midday, and the Institute of the Physics of the Earth of the Soviet Academy of Sciences, the coordinator of the country's seismological service, at 12:02 p.m. Urgent reports continued coming in till $1: 40$ p.m. from 58 seismological stations.

From the incoming data, the following parameters were established: $\tau$ (time) $=$ $7: 41: 23 \cdot 1$ GMT; $\varphi=40 \cdot 82$ degrees lat. $\mathrm{N}$; $\lambda=44.05$ degrees long. $\mathrm{E} ; h$ (depth) $=3$ kilometres; $M$ (magnitude) $=7 \cdot 0$.

Deciphering the data shows that the earthquake began three kilometres beneath the surface with the epicentre at Spitak, between Leninakan and Kirovakan. The shallowness of the earthquake lent it strength and intensity.

From the signs of the P-waves, seismologists have been able to reconstruct the possible earthquake mechanism. There are two alternative fault planes, specified by the following parameters:

$\begin{array}{lccc} & \text { Strike } & \text { Dip } & \text { Slip } \\ \text { NP1: } & 276^{\circ} & 15^{\circ} & 147^{\circ} \\ \text { NP2: } & 38^{\circ} & 82^{\circ} & 78^{\circ} .\end{array}$

The same analysis gives the directions of maximum tension and of compression as azimuth $294^{\circ}$ (plunge $51^{\circ}$ ) and $139^{\circ}$ (plunge $36^{\circ}$ ) respectively. The intermediate direction has azimuth $40^{\circ}$ (plunge $12^{\circ}$ ).

Seismological stations also recorded the following macroseismic tremors on the 12 point Soviet scale: 9 points at Leninakan; 6 to 7 points at Bakuriani, Tabatskuri and Borzhomi; 5 to 6 points at Bogdanovka, Tbilisi and Yerevan; 5 points at Goris; 4 points at Makhachkala; 3 to 4 points at Grozny; and 3 points at Sheki and Shemakha.

Igor Nersesov, head of the Institute of the Physics of the Earth, says that the underlying cause of the earthquake is that "The Arabian plate is moving towards the region from the south, and the accumulated pressure of the movement is released in earthquakes."

There have in the past been powerful earthquakes on the border between Armenia and Turkey, especially between AD 900 and 1000. One of the Armenian seismological stations is situated near Aini, the ancient capital of Armenia

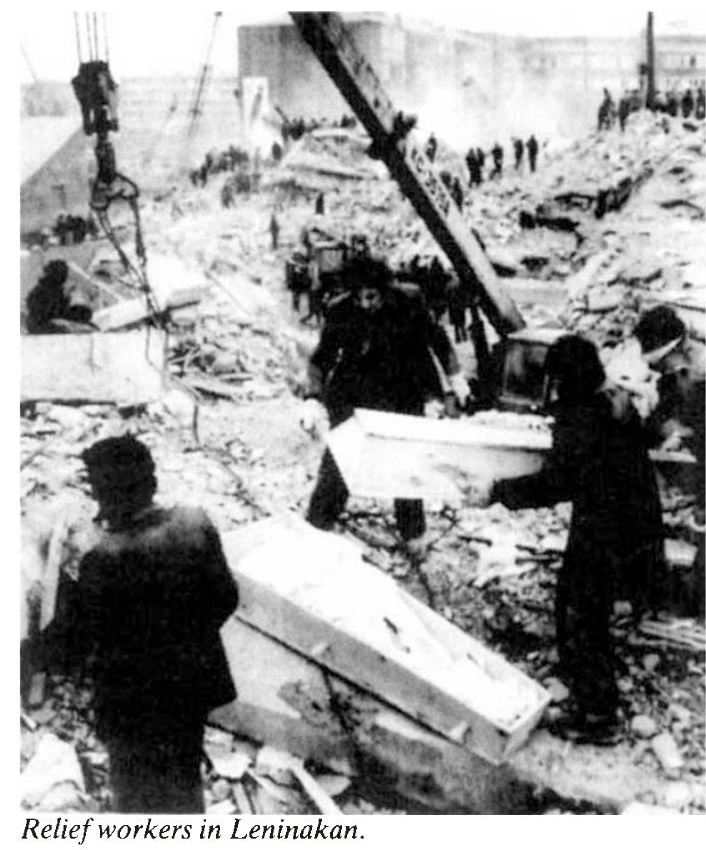

toppled by the earthquake in AD 1046 of 8 to 9 points. The last big earthquake, magnitude 5.7 (about 8 points) was in Leninakan in 1926. But in intensity and the devastation caused, last week's earthquake is comparable with those in Tangshan, China, in 1976 and Mexico City in 1985.

Last week's events were not predicted. But earthquakes usually occur in regions of intense seismic activity and seismic zones are marked on the seismological maps which are used in the Soviet Union, as elsewhere, in architectural design for earthquake-prone areas as well as for earthquake-prediction and risk-reduction measures.

The Politburo commission is still working at Yerevan, but Soviet experts are already very critical of the flawed design and construction which added to the earthquake's heavy toll in Leninakan. Recommendations of scientists and engineers seem to have been largely ignored. It is significant that multi-storey structures built only three years ago crumbled, while the lower houses built twenty and more years ago remained standing

On the question of whether it would have been possible to have predicted the earthquake, no detailed information is as yet available, for telephone lines to the Leninakan seismological station had not been restored by 11 December.

"We do not have the necessary technical facilities for prompt data processing, which is essential for sufficiently accurate forecasting of earthquakes," says Nersesov. "If we had had such facilities, we could probably have predicted the oncoming catastrophe in Armenia and reduce its 
toll."

The leading Soviet seismologist also calls into question the expediency of building nuclear power stations in earthquake-prone regions, even if their design is technologically up to standard. The Armenian nuclear power station designed to withstand tremors of up to 8 points did not suffer in the earthquake, but there was a real risk of damage.

One striking feature of last week's catastrophe is that the Soviet press has been full of information about the disaster. This, a consequence of the leadership's policy of glasnost, is in sharp contrast with the reticence following the disasters in Ashkhabad in 1948 and Tashkent in 1966. One of the side benefits has been that the relief effort has assumed unprecedented proportions.

Meanwhile, the earthquake has made people forget their differences and join forces in grief, compassion and assistance.

Vladimir Markov

Novosti

Vera Rich writes: Markov is certainly correct to describe the handling of the Armenian earthquake as a telling example of how far Soviet glasnost has progressed, even since the Chernobyl disaster of April 1986. Then it was more than 60 hours before an official announcement was made and, even then, the accident was treated as a minor news item. Last week, however, the leading Soviet papers carried at least a brief report in the first available edition, and reversed a long-standing Soviet tradition by carrying disaster coverage on the first page.

The Soviet press also reports that the bureau of the Central Committee of the Communist Party of Armenia was in session when the earthquake struck. The first reaction of the bureau members was to telephone to the Armenian nuclear power station at Medzamor, some $35 \mathrm{~km}$ from Yerevan, as well as to the major chemical enterprises in Armenia.

But so far it has not been remarked that both the nuclear power station and the chemical plants have been during the past three years the subject of an environmental campaign backed by several members of the Armenian Academy of Sciences, which particularly criticized the siting off such establishments in a seismic zone. A few weeks ago, in response to this pressure, it was promised that the Medzamor power station would be phased out by 1991, the earliest date by which alternative energy supplies could be ensured.

Similar concerns have more recently arisen in Tadjikistan, the earthquakeprone mountainous republic further east, where it is claimed that hydroelectric dams have been built using safety factors worked out for single dams in low-lying aseismic areas.

\section{Conflicting views on extent of earthquake threat to Tokyo}

Tokyo

A REPETITION of the Great Kanto Earthquake of 1923 would result in widespread death and destruction in the Tokyo area, according to a report released last week by the National Land Agency. The report has shocked Tokyo residents, but critics say it fails to gauge the full possible extent of the disaster.

Tokyo lies in one of the most earthquake-prone regions of the world second in the list of fast-growing cities 'at risk', on page 626 of this issue. To the east, the Pacific plate plunges beneath Japan and to the south-west the subducting Philippine plate slices into the Izu Peninsula between Suruga and Sagami bays. In 1923, the Great Kanto earthquake, which was centred in Sagami Bay and registered 7.9 on the Richter scale, destroyed large sections of the city and left nearly 150,000 people dead.

To assess the impact of a similar event, the agency divided Tokyo and surrounding prefectures (Saitama, Kanagawa and Chiba) into a 1- or 2-kilometre grid and modelled the effects of the 1923 earthquake on present-day Tokyo, taking into account conditions in each block of the grid. The results suggest a similar death toll to the 1923 event.

Modern buildings within Tokyo are designed to withstand major earthquakes (see below). But in many parts of the city, old wooden houses can still be found squashed together within inches of each other and conditions are ripe for disastrous fires.
If an earthquake should strike in the middle of the night, the death toll would be limited to 80,000 , according to the report. But if it came at lunchtime (as in 1923) or early in the evening in winter when stoves would be lit for cooking or heating, fires could be expected to sweep through parts of the city soon after the earthquake and the number of deaths could reach 150,000 , with another 200,000 injured, the report says.

But some critics say the report may underestimate the full extent of the damage that might be caused by a major earthquake. For example, no account is taken of recent reclamation and development projects along Tokyo Bay waterfront and no estimate is made of the possible death toll resulting from panic in the underground railways and shopping malls scattered around modern-day Tokyo.

Although computers have back-up systems to cover such events, some economists fear that a major earthquake in Tokyo could cause panic on the world market.

The National Land Agency report, which also maps out responsibilities for the various government ministries and agencies in the event of such a disaster, has been submitted to the Central Disaster Prevention Council, chaired by Prime Minister Noboru Takeshita, which will propose counter measures.

But the only effective solution would probably be decentralization and drastic changes in the planning and development of the city.

\section{Builders look to 'anti-quake' device}

JAPANESE engineers have developed an ingenious way to protect tall buildings from earthquakes. A device placed on the top of the building creates 'anti-quakes' to cancel out the effects of earthquake motion.

Tall buildings in Tokyo and other major Japanese cities are designed to flex and sway during earthquakes. The oscillations absorb the earthquake and protect the building from collapse. But the swaying motions can be a frightening experience for people on the top floors even during comparatively minor earthquakes.

Kajima Corporation, a construction company, plans to bring the swinging to a halt with 'anti-quakes'. Kajima's device consists of huge weights (several tons) on wheels placed on the roof of the building. A computer connected to motion and vibration sensors in the basement and mid-floor of the building command hydraulic actuators to move the weights back and forth very rapidly in such a fashion as to cancel

\section{out the forces of the earthquake.}

Kajima researchers say their device can reduce motions up to 75 per cent in earthquakes up to magnitude 4 on the Japanese scale of 7 . Magnitude 4 earthquakes cause buildings to shake violently, knocking over ornaments and glasses. The device is also effective in preventing motions induced by strong winds of up to 70 kilometres per hour.

By May next year, Kajima Corporation will install its first commercial anti-quake device in an 11-storey building now being built in Kyobashi, Tokyo. The device, however, does suffer from one potential hazard. If the timing is slightly out, the moving weights will amplify rather than decrease oscillation of the building. But Mitsuo Sakamoto of Kajima's Kobori Research Institute says that the computer software contains a "fail-safe" program that can switch the system off if things get out of control.
David Swinbanks 